\title{
C-FICOCIANINA INCORPORADA À NANOFIBRAS: DETERMINAÇÃO DE TERMOESTABILIDADE
}

\author{
A. R. C. BRAGA ${ }^{1}$, F. S. FIGUEIRA ${ }^{1}$, J. T. SILVEIRA ${ }^{1}$, P. B. M. SILVA ${ }^{1}$, M. G. MORAIS ${ }^{1}$, J. A. V. \\ $\operatorname{COSTA}^{1}$, S. J. KALIL ${ }^{1}$ \\ ${ }^{1}$ Universidade Federal de Rio Grande, Escola de Química e Alimentos \\ E-mail para contato: annarafaela@gmail.com
}

\begin{abstract}
RESUMO - A C-ficocianina (C-FC) possui características importantes como: ser uma ficobiliproteína natural, de cor azul única, boa solubilidade em água, alta estabilidade na faixa de $\mathrm{pH}$ 5-7,5, fluorescência e propriedades terapêuticas, como atividades antioxidante e anti-inflamatória com aplicação em diagnósticos. É um pigmento natural, e pode ser utilizado na indústria de alimentos, como corante, em sucos e gomas e na indústria de cosméticos, substituindo corantes sintéticos. A incorporação de C-FC em nanofibras é extremamente promissora para sua aplicação em diferentes áreas da biotecnologia. Nesse contexto, o objetivo do presente trabalho foi determinar a cinética de degradação térmica da C-FC purificada incorporada à nanofibras. A C-ficocianina foi submetida a diferentes temperaturas $\left(50-75^{\circ} \mathrm{C}\right)$ e os valores de constantes de desnaturação térmica $\left(\mathrm{K}_{\mathrm{d}}\right)$ e valores de meia-vida $\left(\mathrm{t}_{1 / 2}\right)$ para a ficobiliproteína em cada condição foram determinados. Os valores de meia-vida variaram entre 169,1 e 7701,6 s.
\end{abstract}

\section{INTRODUÇÃO}

As ficobiliproteínas são pigmentos captadores de energia luminosa, presentes em cianobactérias, responsáveis por cerca de $50 \%$ da captação de luz desses micro-organismos. Uma das ficobiliproteínas de particular interesse para a indústria de alimentos e cosméticos é a C-ficocianina; devido a sua vantajosa utilização como um corante natural azul nestes setores (Silveira et al., 2007).

Dentre as fontes existentes deste biocorante, a cianobactéria Spirulina platensis recebe destaque, uma vez que a C-ficocianina pode constituir até $20 \%$ em peso seco das proteínas totais deste micro-organismo. Estudos demonstram que a $\mathrm{C}$-ficocianina, além de ser um biocorante natural, possui propriedades antioxidantes, anti-inflamatória e antitumoral, além de agir como estimulante do sistema imunológico aumentando assim, a contagem de leucócitos totais, cuja principal função é manter a saúde dos órgãos do corpo, proteger contra o câncer e úlceras (Gantar et al., 2012; Ichimura et al., 2013).

A fim de aumentar a utilização e proporcionar novas possibilidades de aplicação deste biocomposto em diferentes áreas, a incorporação de C-FC em nanofibras é potencialmente promissora. Em relação à formação de nanofibras existem diversas técnicas utilizadas para a elaboração das mesmas, no entanto, "electrospinning" é uma técnica que se destaca pois a mesma 
apresenta uma abordagem simples formando nanofibras de comprimento excepcionalmente longo, com diâmetro uniforme e com composições diversificadas (Uyar e Besenbacher, 2009).

Para avaliar as características da C-FC incorporada a nanofibras, em termos de estabilidade térmica, a constante de reação de desnaturação $\left(K_{d}\right)$ e a meia-vida $\left(t_{1 / 2}\right)$ são parâmetros importantes, na literatura consultada até o presente momento, não há trabalhos que avaliem essas propriedades em nanofibras contendo C-FC. Portanto, nesse contexto, o objetivo do presente trabalho foi determinar os parâmetros da estabilidade térmica da C-FC purificada incorporada à nanofibras.

\section{MATERIAL E MÉTODOS}

\subsection{Biomassa, Extração e Quantificação de C-ficocianina}

A cianobactéria Spirulina platensis LEB 52 foi cultivada e cedida pelo Laboratório de Engenharia Bioquímica da Universidade Federal do Rio Grande. A partir da biomassa, C-ficocianina foi extraída de acordo com descrito por Moraes et al., 2010. Após a extração, o caldo bruto contendo células foi centrifugado e ajustado o pH para 6,5. A concentração de C-ficocianina foi calculada utilizando a Equação 1, descrita por Bennett e Bogorad (1973):

$$
C-P C=\frac{\left(O D_{620}-4,74 x\left(O D_{652}\right)\right)}{5,34}
$$

Onde, C-FC é a concentração de C-ficocianina e A620 e A652 são as absorvâncias em 620 e $652 \mathrm{~nm}$, respectivamente.

\subsection{Purificação por Ultrafiltração}

A ultrafiltração foi realizada em célula laboratorial do tipo convencional, de volume útil de 200 $\mathrm{mL}$, agitada por uma barra magnética suspensa, para simulação do escoamento em fluxo cruzado. Foi utilizada membrana de retenção nominal de $50 \mathrm{kDa}$ de polietersulfona, temperatura de $25^{\circ} \mathrm{C}$, pressão de $1,0 \mathrm{kgf} / \mathrm{cm}^{2}$ e pH de 6,5. Foram utilizados 6 ciclos de diafiltração (ciclos de recarga de tampão na célula de ultrafiltração com tampão fosfato de sódio, $\mathrm{pH}$ 6,5), previamente a concentração do extrato. Foi alimentado ao sistema extrato clarificado de C-FC (Figueira, 2014).

\subsection{Formação de Nanofibras}

No processo de electrospinning as soluções foram injetadas através de capilar com diâmetro de $0,45 \mathrm{~mm}$. O eletrodo de polaridade positiva foi conectado a extremidade do capilar e o isolamento foi conectado ao coletor de alumínio. A distância utilizada entre a extremidade do capilar e o coletor foi de $125 \mathrm{~mm}$. O potencial elétrico aplicado foi de $24,3 \mathrm{kV}$. A vazão da solução foi de $2,5 \mu \mathrm{L} \cdot \mathrm{min}^{-1}$, controlada através de bomba ligada ao injetor (Figueira, 2014). Todos os experimentos foram conduzidos em temperatura ambiente e com umidade relativa do ar entre 50 e $60 \%$. 


\subsection{Parâmetros de Estabilidade Térmica de C-ficocianina}

Avaliou-se a cinética de degradação térmica de C-FC incorporada à nanofibras nas temperaturas de $50,55,60,65,70$ e $75^{\circ} \mathrm{C}$, de modo a obter $\mathrm{K}_{\mathrm{d}}$ e $\mathrm{t}_{1 / 2}$ para cada condição proposta. As amostras foram removidas periodicamente até que metade da concentração inicial de C-FC fosse atingida. $\mathrm{O} \mathrm{K}_{\mathrm{d}}\left(\mathrm{s}^{-1}\right)$ de $\mathrm{C}$-FC foi estimado pela regressão dos dados experimentais pelo tempo, assumindo uma cinética de reação de primeira ordem, $\mathrm{K}_{\mathrm{d}}$ foi determinado de acordo com a Equação 2:

$$
\frac{d C_{F}}{d t}=-K d C
$$

Onde $\mathrm{C}_{\mathrm{F}}$ é a concentração de C-FC ( $\left.\mathrm{mg}^{\mathrm{m}} \mathrm{mL}^{-1}\right)$, t é tempo (s) e $\mathrm{K}_{\mathrm{d}}$ a constante de degradação térmica $\left(\mathrm{s}^{-1}\right)$. Os valores de meia-vida foram determinados de acordo com a Equação 3:

$$
t_{1 / 2}=\frac{\ln 2}{K_{d}}
$$

\section{RESULTADOS E DISCUSSÃO}

As nanofibras de óxido de polietileno incorporadas de C-ficocianina, obtidas neste trabalho, foram primeiramente desenvolvidas por Figueira (2014). Na Figura 1 é possível observar, através de microscopia óptica utilizando campo escuro, as nanofibras formadas nas quais se obteve um diâmetro médio de 542,1 nm e se mostraram homogêneas, sem presença de gotas em sua estrutura.

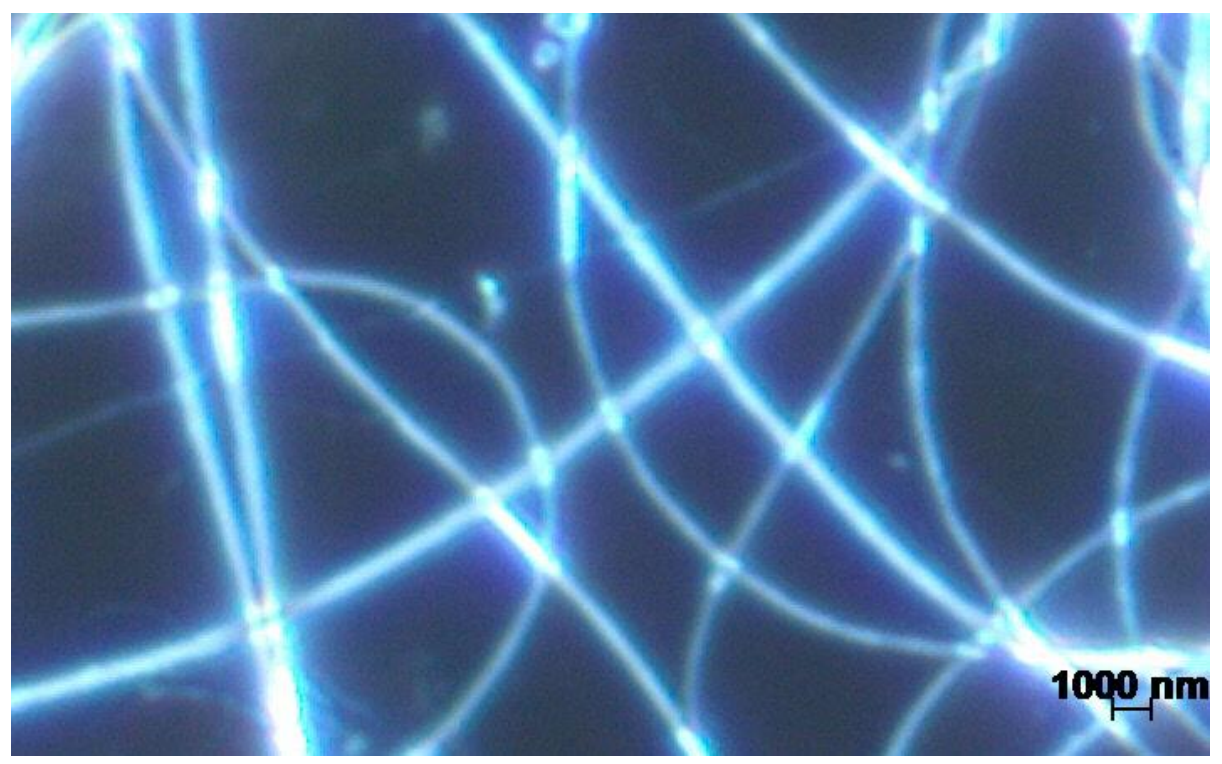

Figura 1: Nanofibras de óxido de polietileno contendo C-ficocianina obtidas a partir do processo de electrospinning 


\section{9 a 22 de outubro de 2014 \\ Florianópolis/SC}

Diversos autores têm estudado a aplicação de modelos de primeira ordem para descrever a termodegradação de produtos coloridos. De acordo com Ávila e Silva (1999) e Corzo et al. (2006) a degradação térmica desses produtos podem ser descritas pelo modelo de primeira ordem. No presente trabalho, usando as equações 2 e 3 , os valores de $K_{d}$ e $t_{1 / 2}$ foram determinados para as diferentes temperaturas a que as nanofibras foram submetidas, esses resultados estão apresentados na Tabela 1.

Tabela 1 - Constante cinética de desnaturação $\left(K_{d}\right)$ e seus respectivos coeficientes de correlação $\left(\mathrm{r}^{2}\right)$, valores de meia-vida $\left(\mathrm{t}_{1 / 2}\right)$ de C-FC incorporada em nanofibras para cada temperatura estudada

\begin{tabular}{|c|c|c|c|}
\hline $\begin{array}{c}\text { Temperatura } \\
\left({ }^{\mathbf{}} \mathbf{C}\right)\end{array}$ & $\mathbf{K}_{\mathbf{d}}\left(\mathbf{s}^{\mathbf{- 1}}\right)$ & $\mathbf{r}^{\mathbf{2}}$ & $\mathbf{t}_{\mathbf{1} / \mathbf{2}}(\mathbf{s})$ \\
\hline 50 & 0,00009 & 0,99 & 7701,6 \\
\hline 55 & 0,0001 & 0,93 & 6931,5 \\
\hline 60 & 0,0006 & 0,94 & 1155,2 \\
\hline 65 & 0,0017 & 0,96 & 407,7 \\
\hline 70 & 0,0035 & 0,96 & 198,0 \\
\hline 75 & 0,0041 & 0,96 & 169,1 \\
\hline
\end{tabular}

Ao avaliarmos a Tabela 1, pode-se observar que nas temperaturas de 50 e $55^{\circ} \mathrm{C}$, as meia-vidas são superiores a 1 hora. A diminuição da meia-vida (de 7701,6 para 6931,5 s) quando aumentou-se a temperatura de análise de 50 para $55^{\circ} \mathrm{C}$ é bem mais suave do que quando altera-se a temperatura de 55 para $60^{\circ} \mathrm{C}$ (de 6931,5 para $1155,2 \mathrm{~s}$ ). Esse comportamento também foi reportado por outros autores que estudaram a estabilidade da C-FC em solução e os mesmos explicam que essas diferenças ocorrem porque a desnaturação térmica desse bioproduto ocorre em diferentes estágios.

Chaiklahan et al. (2012) avaliaram a estabilidade de ficocianina de grau alimentar extraída de Spirulina sp. e identificaram três fases de degradação diferentes. Segundo estes autores, na primeira fase $\left(26-43{ }^{\circ} \mathrm{C}\right)$, as soluções de ficocianina mostraram uma lenta taxa de degradação. Durante a segunda fase, a taxa de degradação aumentou drasticamente à medida que a temperatura de incubação foi aumentada de $47-64^{\circ} \mathrm{C}$. Novos aumentos na taxa de degradação foram mínimos durante a terceira fase, quando a temperatura foi maior que $64^{\circ} \mathrm{C}$.

Verificou-se que a degradação da fração proteica da C-ficocianina incorporada em nanofibras seguiu um modelo de cinética de primeira ordem, esse fato pode ser comprovado pelos elevados coeficientes de correlações (de 0,93 a 0,99 ) obtidos para a determinação da constante cinética de desnaturação. Verificou-se também que a C-ficocianina foi desnaturada mais rapidamente a temperaturas mais elevadas, desde que os valores de meia-vida (tempo necessário para que a concentração inicial de C-FC seja reduzida para metade) diminuiu à medida que aumentou-se a temperatura de trabalho. O mesmo foi observado por Koca et al. (2007) para a clorofila de grãos de ervilha, em que a meia-vida do pigmento foi reduzida com o aumento da temperatura de trabalho. Antelo et al. (2008) também verificaram o mesmo comportamento para a cinética de degradação térmica do extrato bruto aquoso de C-ficocianina de S. platensis. 


\section{9 a 22 de outubro de 2014 \\ Florianópolis/SC}

\section{CONCLUSÕES}

Através dos resultados obtidos pode-se evidenciar a grande potencialidade de aplicação de Cficocianina incorporada a nanofibras. As propriedades determinadas demonstram que nas temperaturas de 50 e $55^{\circ} \mathrm{C}$ as nanofibras contendo $\mathrm{C}$-FC permanecem os valores de meia-vida são maiores que uma hora.

\section{AGRADECIMENTOS}

Os autores agradecem a CAPES, CNPq e FAPERGS pelo apoio financeiro a este trabalho.

\section{REFERÊNCIAS}

ANTELO, F. S.; COSTA, J. A. V.; KALIL, S. J. Thermal degradation kinetics of the phycocyanin from Spirulina platensis. Biochem. Eng. J., v. 41, p. 43-47, 2008.

ÁVILA, I. M. L. B.; SILVA, C. L. M. Modelling kinetics of thermal degradation of colour in peach puree. J. Food Eng., v. 39, p. 161-166, 1999.

BENNETT, A.; BOGORAD, L. Complementary chromatic adaptation in a filamentous blue-green alga. J. Cell Biol., v. 58, p. 419-435, 1973.

CHAIKLAHAN, R.; CHIRASUWAN, N.; BUNNAG, B. Stability of phycocyanin extracted from Spirulina sp.: Influence of temperature, $\mathrm{pH}$ and preservatives. Process Biochem., v. 47, p. 659-664, 2012.

CORZO, O.; BRACHO, N.; MARJAL, J. Color change kinetics of sardine sheets during vacuum pulse osmotic dehydration. J. Food Eng., v. 75, p. 21-26, 2006.

FIGUERIA, F. S. Purificação de C-ficocianina e sua incorporação em nanofibras. Tese de Doutorado (Universidade Federal do Rio Grande), 2014.

GANTAR, M.; SIMOVI-Ç, D.; DJILAS, S.; GONZALEZ, W. W.; MIKSOVSKA, J. Isolation, characterization and antioxidative activity of C-phycocyanin from Limnothrix sp. strain 37-2-1. J. Biotechnol., v. 159, p. 21-26, 2012.

ICHIMURA, M.; KATO, S.; TSUNEYAMA, K.; MATSUTAKE, S.; KAMOGAWA, M.; HIRAO, E.; MIYATA, A.; MORI, S.; YAMAGUCHI, N.; SURUGA, K.; OMAGARI, K. Phycocyanin prevents hypertension and low serum adiponectin level in a rat model of metabolic syndrome. Nutr. Res., v. 33, p. 397-405, 2013.

KOCA, N.; KARADENIZ, F.; BURDURLU, H. S. Effect of pH on chlorophyll degradation and colour loss in blanched green peas. Food Chem., v. 100, p. 609-615, 2007.

MORAES, C. C.; BURKERT, J. F.; KALIL, S. J. C-Phycocyanin extraction process for large-scale 
use. J. Food Biochem., v. 34, 2010.

SILVEIRA, S. T.; BURKERT, J. F. M.; COSTA, J. A. V.; BURKERT, C. A. V.; KALIL, S. J. Optimization of phycocyanin extraction from Spirulina platensis using factorial design. Bioresour. Technol., v. 98, p. 1629-1634, 2007.

UYAR, T.; BESENBACHER, F. Electrospinning of cyclodextrin functionalized polyethylene oxide (PEO) nanofibers. Eur. Polym. J., v. 45, p. 1032-1037, 2009. 